This item was submitted to Loughborough's Research Repository by the author.

Items in Figshare are protected by copyright, with all rights reserved, unless otherwise indicated.

\title{
Institutional and cultural barriers to transferring Lean production to China: evidence from a German automotive components manufacturer
}

PLEASE CITE THE PUBLISHED VERSION

http://dx.doi.org/10.1057/abm.2014.18

\section{PUBLISHER}

(c) Palgrave Macmillan

\section{VERSION}

AM (Accepted Manuscript)

\section{PUBLISHER STATEMENT}

This work is made available according to the conditions of the Creative Commons Attribution-NonCommercialNoDerivatives 4.0 International (CC BY-NC-ND 4.0) licence. Full details of this licence are available at: https://creativecommons.org/licenses/by-nc-nd/4.0/

\section{LICENCE}

CC BY-NC-ND 4.0

\section{REPOSITORY RECORD}

Zimmermann, Angelika, and Marc Bollbach. 2019. "Institutional and Cultural Barriers to Transferring Lean Production to China: Evidence from a German Automotive Components Manufacturer". figshare. https://hdl.handle.net/2134/16653. 
Institutional and cultural barriers to transferring Lean production to China: Evidence from a German automotive components manufacturer

\begin{abstract}
Our qualitative study of a globally operating German automotive components manufacturer demonstrates how certain cognitive dispositions and behaviours of Chinese employees acted as barriers to the transfer of the firm's Lean production system to its subsidiaries in China. We analyse how these barriers were rooted in the Chinese institutional and cultural context, thereby contributing a new micro-level perspective to business systems literature. Our findings further suggest that manufacturing in China will not be truly 'Lean' in the near future, which may place constraints on China’s technological development at a larger scale.
\end{abstract}

Key words: practice transfer, business system, China, Lean, manufacturing, production, institution, culture 


\section{Introduction}

China has become a prime manufacturing location for Western firms, who have established production facilities there in the hope of lower labour costs, higher profit margins, and the potential of a vast and growing market. These firms tend to use established operational practices of Lean manufacturing, aiming at high levels of process efficiency and product quality. To connect China's manufacturing potential with the efficiency of Lean philosophy is therefore a major goal in the emerging global marketplace. At the same time, the transfer of the Lean production systems of Western firms to China is constrained by severe barriers (e.g. Aminpour and Woetzel, 2006; Oliver et al., 1998). To facilitate the successful transfer of Lean production systems, it is necessary to understand these barriers as well as their root causes in the Chinese country context.

As yet, researchers have not systematically addressed why barriers arise in the Chinese context and how they affect the Lean system. Given this lack of prior research, we used an inductive case study of a German globally-operating automotive parts supplier to identify a range of barriers to Lean transfer at the level of the cognitive dispositions and behaviours of Chinese members of the firm's subsidiaries and supplier firms. Drawing on our respondents' reports as well as concepts of transnational practice transfer (Kostova, 1999) and the Chinese business system (Redding and Witt, 2007, 2014), we explain how these barriers originate in Chinese institutional and cultural contexts.

In what follows, we will first provide a brief introduction to the core principles of Lean manufacturing. We then review prior studies on Lean manufacturing in China, as well as relevant concepts regarding transnational practice transfer and national business systems. This leads to the research questions of this study, followed by the methods section. We present our 
results regarding deficiencies in the Lean production system, barriers to the transfer of Lean to China, and their roots in Chinese institutional and cultural context. After this, we raise questions on the need to adapt to the Chinese context, followed by a discussion of our contributions to the literatures on transnational practice transfer and national business systems. We conclude by outlining limitations of the study and directions for future research.

\section{Lean Manufacturing}

The idea of Lean manufacturing came to prominence in the late 1980s. Based on their study on the world's automotive industry's performance in the 1980s, Womack et al. (1990) highlighted how Japanese automotive production plants achieved higher productivity and quality than Western plants. The researchers named the Japanese manufacturing model 'Lean manufacturing'. This term has since been associated with the practice of distinguishing valueadding activities from waste activities, both within an organisation and in its supply chain (Comm and Mathaisel, 2005). Lean manufacturing provides a way of doing more with less less human effort, less equipment, less time, and less space (Womack and Jones, 2003) - by following five core principles: (1) specifying value by specific products, (2) identifying the value stream for each product, (3) making value flow without interruptions, (4) letting the customer pull value from the producer, and (5) pursuing perfection (Womack and Jones, 2003).

More specifically, Womack and Jones claim that Lean thinking must start with a value definition in terms of products with specific capabilities, through dialogue with specific customers. Every feature of a product or service not valued by the customer is regarded as 'waste'. The steps within the value stream are hence classified into those that create value, 
those that do not create value but are unavoidable, and those that do not create value and are immediately avoidable. Waste can be found in overproduction, waiting times, transportation, processing, inventory, movement, and production of defective parts (e.g. Slack et al., 2004).

A common practice to prevent defects and thus wasteful production are line stops by workers. If, during production, defects or abnormal situations arise, line workers are empowered to stop the entire production line. Based on the stoppage of the entire line, other operators cannot continue their work and are instructed to investigate the problem and take necessary corrective actions. Forcing immediate attention to the problem, an investigation into its root cause and initiation of corrective action may prevent similar defects from occurring again. In addition, preventive maintenance of machinery before it breaks down contributes to lower risks of interruption to production flow.

Lean manufacturing also requires that value-creating steps closely flow together. Traditional mass production systems use inventory as buffers between each production step to allow for production in an uninterrupted and consequently locally efficient way at each stage of the process. Lean, however, and more precisely its Just-in-Time (JIT) principle, avoids such isolation of stages. Production in the upstream workplace is initiated by orders from the downstream workplace, leading to 'one or single-piece flow' production. Given the missing buffers between up and downstream workplaces, the workplaces are interdependent. When problems at a single workplace occur, all other workplaces are affected, and workers need to join in solving problems instantly rather than allowing problems to be passed down the production line.

Lean production also follows a pull-demand signal, whereby the customer 'pulls' the product from the firm rather than the firm 'pushing' products into the market. Lean firms 
design, schedule, and produce precisely what the end-customer wants and when they want it. This system ensures that only actually-needed parts and material are brought to the production line, thus reducing inventories and helping to minimize waste.

Lean further requires companies to pursue perfection by applying all principles until ideal value is created without waste (Womack and Jones, 2003). This is achieved through continuous improvement or 'kaizen'. In comparison to traditional production, where improvement activities take place infrequently in response to major changes, kaizen aims to improve processes of the system continuously and incrementally (Bicheno and Holweg, 2009). Improvements have to be initiated actively by all employees, including the shop floor (Ohno, 1988), which demands the participation and responsibility of the entire workforce.

\section{Lean manufacturing in China}

To our knowledge, there is little research on the transfer of Lean manufacturing methods to China. Moreover, the few extant studies do not provide a systematic overview of barriers to Lean transfer, and hardly discuss country-context factors that may be at the root of such difficulties. With a few notable exceptions (e.g. Oliver et al., 1998), existing researches draw only on small-scale, anecdotal evidence.

Extant research does, however, provide clear indications that Lean production systems in China face serious difficulties. Authors report cases where product quality was unsatisfactory (Aminpour and Woetzel, 2006; Aoki, 2008; Chin and Pun, 2002; Comm and Mathaisel, 2005; Lee, 2004; Oliver et al., 1998; Paolini et al., 2005), workplace organisation tools could not be utilized (Chen and Bo, 2008; Paolini et al., 2005), it was not possible to realize continuous improvement (e.g. Aminpour and Woetzel, 2006; Aoki, 2008; Oliver et al., 
1998; Paolini et al., 2005), or JIT production and low inventory levels were not achieved (Aminpour and Woetzel, 2006; Oliver et al., 1998).

From our reading of these studies, we can discern seven potential barriers to Lean transfer in China: lack of technical and Lean knowledge, lack of initiative and participation, tolerance of untidiness, high employee turnover, management styles, missing long-term strategy, inadequate quality control procedures, and weak supplier performance.

Lack of technical and Lean knowledge has been regarded as a major impediment to Lean manufacturing in Chinese plants (Aminpour and Woetzel, 2006; Brown and O’Rourke, 2007; Lee, 2004; Oliver et al., 1998; Paolini et al., 2005). Well-educated workers with Lean manufacturing experience are rare in the job market. Moreover, driven by cost-saving strategies, many factories intentionally attract poorly educated workers from rural areas, from agricultural villages with little exposure to basic manufacturing techniques, let alone Lean production principles (Brown and O’Rourke, 2007; Oliver et al., 1998; Paolini et al., 2005).

Along with the lack of knowledge, several authors address a lack of initiative and participation of workers as severe impediment to Lean manufacturing in China (Aoki, 2008; Chen and Bo, 2008; Chin and Pun, 2002; Lee, 2004; Paolini et al., 2005; Taj, 2005). To illustrate, Aoki (2008) describes a lack of initiative among Chinese shop-floor workers in a Japanese firm trying to transfer kaizen activities to overseas plants in China. Japanese management in this firm found it difficult to encourage Chinese workers to take initiatives, and only employees above team-leader levels made suggestions for process improvements. Similarly, Chin and Pun (2002) report on a lack of participation. Operators and supervisors were seen to be unwilling to contribute to improvements, or unaware of how to do this. 
A few researchers further address a tolerance of untidiness within Chinese workers as an obstacle to Lean. Paolini et al. (2005) report that Chinese workers' tolerance for an untidy or disorganized workplace conflicted with housekeeping tools such as 5S. Similarly, Wong (2007) observed an ignorance of accuracy by Chinese workers.

High employee turnover has been described a major obstacle to Lean production in China (Aminpour and Woetzel, 2006; Aoki, 2008; Brown and O’Rourke, 2007; Paolini et al., 2005; Taj, 2005). For example, Taj indicates that 10 per cent of the companies taking part in their survey reported an annual employee turnover of more than 30 per cent. It is apparent that such high employee turnover makes it very hard to develop the missing technical expertise and Lean knowledge mentioned above.

Several authors highlight how Chinese management styles impede the application of Lean manufacturing in Chinese plants (Aminpour and Woetzel, 2006; Aoki, 2008; Brown and O’Rourke, 2007; Chin and Pun, 2002; Lee, 2004; Oliver et al., 1998; Paolini et al., 2005; Taj, 2005; Wong, 2007). According to Lean philosophy, shop-floor workers need to be empowered to suggest and conduct improvements from the bottom up (Liker and Meyer, 2007). Such empowerment is however relatively new to Chinese managers (Oliver et al., 1998). In Aoki’s (2008) case study, for example, Chinese employees beyond team-leader level did not feel authorized to make suggestions for process improvements. Similarly, Aminpour and Woetzel (2006) discern that the hierarchical nature of Chinese organisations hinders the cooperation and joint decision-making needed for problem-solving as part of Lean, and Paolini et al. (2005) report on a general top-down approach, with middle managers being afraid of losing authority when empowering employees as part of Lean implementation. 
A central principle of Lean is that all decisions have to be made on a long-term basis, even if this results in additional effort in the present. Several authors observe that Chinese managers in Lean manufacturing plants lack such a long-term strategic orientation (Aminpour and Woetzel, 2006; Chen and Bo, 2008; Chin and Pun, 2002; Comm and Mathaisel, 2005; Oliver et al., 1998; Paolini et al., 2005). Aminpour and Woetzel (2006), for example, explain that managers focused on 'fighting fires' rather than on long-term implementation of Lean. In the same vein, Aminpour and Woetzel (2006) and Paolini et al. (2005) perceived that managers allocated too short ramp-up periods when launching new product lines, leading to quality problems. Managers thus underestimated the time required for the training and refining processes necessary for achieving Lean principles such as continuous improvement and waste elimination.

Inadequate quality control procedures seem to be another barrier to Lean manufacturing in Chinese plants (Aminpour and Woetzel, 2006; Aoki, 2008; Chin and Pun, 2002; Comm and Mathaisel, 2005; Lee, 2004; Oliver et al., 1998; Paolini et al., 2005). Researchers have observed that quality control procedures were poor in cases where product quality was not monitored sufficiently during the production process (Oliver et al. 1998; Lee, 2004), production time was not calculated, and too little documentation was used (Comm and Mathaisel, 2005).

Weak supplier performance has often been highlighted as a barrier to Lean in China (Comm and Mathaisel, 2005; Taj, 2005; Oliver et al., 1998; Paolini et al., 2005; Lee, 2004). Suppliers have been described as unreliable with regard to quality and on-time delivery, both of which are required for JIT production and low inventory levels at the client firm. As a consequence, many Chinese manufacturers and joint ventures tend to depend on key parts or 
machinery from overseas companies or their parent firm abroad. Such imports, however, require long delivery times (Comm and Mathaisel, 2005) and can be further delayed through long customs procedures (Paolini et al., 2005), making it difficult to produce JIT without warehousing key parts (Comm and Mathaisel, 2005; Lee, 2004).

Barriers of this kind (for example a lack of knowledge and inappropriate management styles) would impede Lean implementation in any country. However, prior research on Lean in China suggests that these barriers are more prevalent in China than in the West or Japan. We scrutinize this suggestion by examining whether and how Lean implementation barriers are tied to the Chinese country context. Where relevant, we will highlight how this context differs from German and Japanese contexts. To examine the influence of the Chinese context on the transfer of Lean, we will draw on the literatures of transnational practice transfer and national business systems.

\section{Transnational practice transfer and the Chinese business system}

The transfer of a Lean production system from a Western to the Chinese context can be regarded as a case of transnational practice transfer. As outlined by Kostova (1999: 311), transnational practice transfer is successful to the extent that it becomes institutionalized at the recipient unit. Institutionalisation means that the practice is both implemented, i.e. the recipient unit follows the formal rules implied by the practice, and internalized, i.e. employees at the recipient unit accept and approve of the practice and adopt it as part of their organisational identity.

According to Kostova's framework, transnational practice transfer is affected by the social, organisational, and relational contexts of the recipient unit. Our focus is here on the 
social context, and more specifically on Chinese institutions and culture. We acknowledge that culture has often been regarded as part of the informal institutions that underpin formal institutions (see Cantwell et al., 2010; Peng et al., 2008). Nevertheless, we preserve the distinction between culture and institutions in order to highlight the importance of culture as such. We thus follow Hofstede et al.’s (2002: 800) concept of culture as a 'substratum', rather than component, of institutions.

Transnational practice-transfer studies (e.g. Eden and Miller, 2004; Gaur et al., 2007; Kostova, 1999; Peng et al., 2008) commonly argue that organisational practices are shaped by their original institutional environment and are therefore not always consistent with the institutional environment to which they are transferred. For this reason, the success of practice transfer is seen to depend on the institutional distance between home and recipient units. Greater institutional distance does, for example, create greater 'relational hazards', due to a firm’s unfamiliarity with host-country institutions (Eden and Miller, 2004). Following Scott's (1995) definition of institutions, these transnational practice-transfer studies tend to examine institutional distance with respect to the home and recipient units’ regulatory institutions (existing laws and rules), cognitive institutions (shared cognitive categories) and normative institutions (values and norms)

It is important to note here that a country’s institutional context exists not just in its formal institutions (such as governmental and educational institutions), but also in the cognitive and normative dispositions that guide the behaviour of the members of the institutional context, who are thus 'carriers of the institutionalized knowledge of the society' (Kostova, 1999: 315). We follow this definition of institutional context, by examining how 
this context is manifested in certain cognitive dispositions and behaviours of organisational members.

Jackson and Deeg (2008) have highlighted that research on institutional distance ignores the potential importance of particular combinations of institutional factors, by aggregating the host of institutional factors of a country context into a single measure of institutional distance. By contrast, studies on national business systems examine how certain institutional factors are systemically interdependent and thereby constitute configurations (or typical cases) of institutional factors that are specific to certain countries. Following this line of reasoning, Redding and Witt (2007; Witt and Redding, 2014) describe the Chinese business system with regard to a broad set of interdependent elements. They highlight how a particular combination of cultural and institutional determinants is at the route of China-specific structures and systems for coordinating economic behaviour and exchange, which include particular mechanisms of ownership, networks, and management. Our approach accords with the business-systems perspective (and diverges from the notion of institutional distance) by exploring the particular combination of interrelated institutional and cultural context factors that are relevant for the transfer of Lean to China. These factors are thus a subset of the institutional and cultural factors in the Chinese business system.

Redding and Witt's (2007) model of the Chinese business system acknowledges that members of Chinese society (such as managers and workers in organisations) are the actors in the system. For example, workers and managers are seen to follow a non-participative management logic, based on the traditional authority of the 'lao ban' (big boss) of familyowned firms. Foremost, however, their model describes the business system at the levels of country and firms, rather than the level of actors. Our study takes a different approach, by 
singling out certain actor characteristics, namely cognitive dispositions and behaviours of Chinese employees of the firm and supplier firms, which we interpret in relation to the Chinese institutional and cultural context. We will hence demonstrate how the institutional and cultural context affects Lean transfer through these actor characteristics.

Following the rationale of our literature review, we conducted a qualitative case study to gain a more comprehensive and in-depth understanding of the transfer of a Lean manufacturing system of a German automobile supplies firm to manufacturing sites in China. We gathered the perspectives of Chinese and German employees of the German automotive supplies company in two production plants in China to answer the following research questions (RQs):

RQ1: What are the main barriers to the transfer of the Lean system to China?

RQ2: How do these barriers affect Lean principles?

RQ3: Are these barriers linked to the Chinese institutional and cultural context, and how?

\section{Methods}

Our inquiry followed a qualitative, interpretivist methodology. In line with Geertz’s (1973) suggestions, we regard the data as our constructions of the respondents' constructions of their social reality. More specifically, we obtained the respondents' accounts of the Lean transfer process, and analysed them in the light of theoretical constructs such as Lean principles and the Chinese business system.

Qualitative methods are particularly suitable for investigating social phenomena from the actors’ perspective, and for exploring new research questions (Denzin and Lincoln, 1994). The use of case study allowed us to explore the nature of the barriers to Lean transfer in a 
particular company and country context, in line with Yin’s (2003) classic recommendations. Our methods were further designed to achieve ‘credibility' and 'transferability', two important criteria for judging the quality of qualitative research (Lincoln and Guba, 1999). To achieve credibility, we followed the principles of theoretical sampling, prolonged engagement, and negative case analysis (see Schwandt, 2007), as detailed below. To allow for transferability, we provide a 'thick' description of the study context, enabling other researchers to examine whether the findings transfer to similar contexts.

\section{Setting}

The automotive industry provides a particularly useful setting for examining barriers to the transfer of Lean, and their associations with the country context. The concept of Lean was originally developed in this industry and has been refined there over a long period, which makes it easier to distinguish between universal barriers to the transnational transfer of Lean systems and those caused by a particular national context. In other areas, such as banking or healthcare, Lean is a relatively recent phenomenon, making it harder to differentiate between barriers caused by transferring Lean manufacturing techniques to the service sector as opposed to barriers caused by the national context.

The German automobile industry in particular is a useful setting for studying Lean transfer, as it has to large extents adopted the original Lean principles (Jürgens, 2003). This is despite Streeck’s (1996) concerns that the German, compared to the Japanese, institutional environment does not fulfil the conditions for Lean, particularly with regard to its smaller degrees of firm-specific vocational training and necessary lifelong employment in a firm. We will later see that these potential incompatibilities of German institutions with Japanese Lean 
principles appear very minor compared to those of the Chinese institutional and cultural context.

We obtained our data in a globally operating German automotive component manufacturer that had been represented in China for several decades. For a number of years, the firm's headquarters had made intensive efforts towards the worldwide implementation of the company’s own Lean production system. This Lean system was explicitly designed according to the core principles of the original Toyota system and had been applied successfully in the firm's German sites.

With the help of previous work contacts, we secured headquarters' approval of the study. We then used this approval to contact two plants in China which manufactured similar products. Qualitative research findings are more robust if they hold in different, but comparable, settings (see Lincoln and Guba, 1999), in this case similar production systems (for example regarding assembly-line design, employee numbers within assembly lines). At the same time, contextual differences between cases (such as location) can reveal the influence of these differences. By keeping the influence of the product and organisational features stable, we were thus able to investigate the influences of the two plants' different geographic location, and their different level of maturity.

We included two production plants of the firm, one in Changsha in midland (southcentral) China, and the other in Suzhou in the Yangtze River Delta economic development zone, near the highly developed coastal belt. Changsha as a city is less industrialized than Suzhou, but has seen strong development over the last years. Low labour costs and huge volumes of workers from nearby rural areas have attracted many foreign firms to set up manufacturing plants, including the participating company site in 2005. The plant produced 
small electrical motors for automobile manufacturers, including starter motors, alternators, blower motors, condenser motors, window-lift motors, cooling motors, and wiper motors. At the time of data collection (spring 2010), the plant had around 1000 employees, with plans for further significant expansions.

Suzhou, in turn, is a well-established industrial area, where multinational firms have set up manufacturing sites over several years. Due to the competitive environment and proximity to Shanghai, labour costs are significantly higher than in Changsha. The plant's main products are small automotive components, such as brake systems and chassis control systems. The plant was founded in 1999. By the time of the study, it comprised c.1000 employees, with plans for further expansion. Given that the two plants differed with regard to their maturity and proximity to the most highly developed coastal region of China, we were able to examine how the barriers to Lean transfer depended on the stages of a subsidiary's development and its immediate environment, and how the barriers were therefore likely to change over time.

\section{Data collection}

The second author, a German national, conducted semi-structured interviews with sixty participants: fifteen German, one Spanish, and fifteen Chinese employees in Changsha; and two German, one French, and 26 Chinese employees in Suzhou (see Appendix for participant details). The small number of Western participants in Suzhou accords with the small number of expatriates in this plant. Six main departments were included in Changsha and four in Suzhou, as well as a cross-divisional Lean implementation team in each plant, which 
consisted of Lean experts and implementation managers. Following the terminology used by the respondents, we distinguish between management and office level ${ }^{1}$. The majority of respondents at both levels held a university degree, typically in engineering (except for members of the HR department). Most respondents had obtained hands-on experience of working on the production line alongside a grounded knowledge of Lean principles. The attempt to include shop-floor workers failed, due to language difficulties and power differentials, even when using a translator.

The interviews were conducted in English for the Chinese, Spanish, and French respondent, and in German for the German participants. The interviews lasted between 30-45 minutes, with an average of 36 minutes. They were all tape-recorded, apart from one, for which extensive notes were taken. The structure of the interviews was determined largely by the respondents' emphasis and emergent themes, but an interview guideline served to cover the core questions, which were adjusted continuously. After introducing the general research aims and confidentiality assurance, the researcher asked respondents about their age, tenure, experience, position, responsibilities in the company, and their estimated knowledge about Lean production principles. Respondents were then asked for their judgment on how well the Lean system worked in China compared to Germany, and reasons for difficulties. Where necessary, more directed questioning was used to cover the main potential barriers to the Lean transfer. At the final stage of the interviews, these directed questions included aspects of the supply chain, time planning, inventory levels, intercultural interactions, work styles, employee turnover, education and knowledge, management styles, and HRM practices. Respondents were also asked to explain whether the barriers were affected by the Chinese country context, 
particularly regarding communication styles, work styles, cultural and demographic characteristics and infrastructure, as well as political, historical, and economic factors.

The researcher made additional use of contextual documents, namely organizational charts, the plants’ monthly newsletter, the worldwide company magazine, and product brochures. These served to obtain information on company culture, products, and the country context. Illustrations and figures on the visual boards within the assembly lines provided an impression of the number and types of quality deviations during the assembly process. Reallife observations were made during guided shop-floor visits throughout the researcher's twomonth stay in China. For example, the researcher observed how workers continued to work on their tasks even when they should have assisted a colleague in solving a machine stoppage, as required by the one-piece flow principle of Lean.

\section{Data analysis}

During the fieldwork phase, the interviewer began creating codes to capture themes derived from the literature, as well as emergent themes. New themes were incorporated into each subsequent interview, leading to an iterative process of data collection and analysis. After the fieldwork phase, all interviews were transcribed and coded in NVivo (QSR) software, using the codes developed during the fieldwork. By reading through all the transcripts, the data were organized through clustering and merging of codes, and themes mentioned by only a very small number of interviewees were excluded.

NVivo node lookups then served to compare the responses on barriers, effects on Lean principles, and context factors between (a) the two sites, (b) Western and Chinese participants, and (c) different hierarchy levels (managers versus office employees). Throughout the data 
analysis of each barrier, a model was developed to capture the detailed description of the barrier, its effects on Lean principles, and the country-context factors. When responses of different participant groups were contradictory, explanatory factors were identified. This negative case analysis fed into the continuous refinement of the model of barriers, effects on Lean, and context factors across sites and respondent groups (summarized in Figure 1). Due to the lack of prior research on the matter, the models were derived to a large extent inductively.

\section{Results}

Our respondents provided vivid accounts of difficulties in transferring the company's Lean production system to the Chinese context. Respondents from both sites, all nationality groups, and all levels of the hierarchy provided consistent reports on the nature of the barriers, their effect on Lean principles, and their root causes in the Chinese country context. The accordance of views provides strong support for our model. These respondent groups did, however, vary in their views on the gravity of certain barriers. Firstly, we observed that Western expatriates tended to portray certain barriers as a larger threat to Lean transfer than the Chinese respondents did. This difference in perception could be due to the expatriates' closer experience of the Lean system in Germany, allowing them to better evaluate its comparative performance. In the same vein, managers, compared to office employees (apart from members of the Lean implementation team), tended to demonstrate a more thorough understanding of the negative effects that the barriers had on the transfer process. This can be attributed to their broader overview of the performance of the entire production system. There were also slight differences between the two locations with regard to the perceived severity of the barriers, which will be mentioned throughout below. In what follows, we present the 
respondents' description of deficiencies in the Lean system, followed by their explanations through barriers and underlying context factors.

Deficiencies in the firm's Lean production system in China

At the time of data collection, the Lean production system was working unsatisfactorily in both the Suzhou and Changsha plants. Target product-quality standards had not been met, and several core principles of Lean production had not been achieved. In particular, the plants had been unable to achieve low levels of waste and inventory, a constant production flow, onepiece flow, or JIT production. They had also been unable to utilize Lean tools appropriately, realize continuous improvement or preventive maintenance, or build a reliable supplier network. Lean principles had thus not been fully implemented. In what follows, it will become clear that they were also far from being internalized by the local workforce.

Barriers to the transfer of the Lean system to China

As reasons for the difficulties, participants described six main barriers. Five of these can be defined as cognitive dispositions or behaviours of the company's workforce: (1) lack of Lean knowledge, (2) lack of systematic problem-solving, (3) high employee turnover, (4) disregard of procedures and standards, and (5) intercultural communication difficulties. The sixth barrier, (6) weak supplier performance, resulted from certain cognitive dispositions and behaviours of local suppliers. We will now outline the respondents' accounts of these barriers, their interrelations, the relevance of the barriers to Lean production principles, and their root causes in the Chinese country context. An overview of these results is provided in Figure 1. 
Lack of Lean knowledge. According to our respondents, most shop-floor workers did not know about Lean production when they entered the company, and even university engineering graduates had only a very limited knowledge and understanding of Lean and its benefits (see quote 1 [q1], Table 1). This lack of Lean knowledge affected the implementation and internalisation of several Lean principles. Employees did not focus sufficiently on waste elimination, especially the elimination of less visible waste such as unnecessary transportation of goods (q2, Table 1). Due to their lack of Lean knowledge, the logistics department failed to achieve 'production levelling', as they paid insufficient attention to levelling out the demands actually needed in daily production and the supplier parts delivered to the temporary warehouse, thus creating waste in the form of temporary space. For similar reasons, 'preventive maintenance' was not achieved. Supervising engineers did not understand that preventive replacements were necessary in order to avoid even slight deviations from the production schedule through machine breakdown, which could lead to major interruptions in the production flow. The one-piece-flow rule, in turn, was broken when shop-floor workers continued working and piling up produced parts, even though a downstream workstation was stopped because of a problem, thus creating buffers of unfinished products. Moreover, the absence of Lean knowledge on the shop floor made it hard to apply 'continuous improvement' from the bottom up. 
Interviewees attributed the lack of Lean knowledge to several institutional-context factors. Institutional education was seen as the most important reason. According to the managers and Chinese engineers, Lean manufacturing was not part of even the most technical university courses. ${ }^{2}$ Operators, in turn, had usually obtained only a very basic level of institutional education (q3, Table 1), making it hard for them to use even simple tools such as fishbone diagrams, let alone grasp the complex links within the production system. Due to China's recent industrialisation, Lean systems were also uncommon within Chinese industry in general, and employees therefore did not have a great chance of prior exposure to Lean. Notably, we found certain inter-regional differences. Due to the greater proximity of the Suzhou plant to the developed coastal region, it was easier to find Chinese recruits who had been educated in a more Western style, or had previously worked in a Western firm. Both in Changsha and Suzhou, however, the few Lean specialists were in high demand given the rapidly developing manufacturing industry, and were therefore particularly hard to recruit and retain.

Lack of systematic problem-solving. Systematic problem-solving is an essential requirement of Lean. Employees at all levels need to be able to detect problems occurring in the production process and find their root causes, in order to take countermeasures, improve the process, and ensure a problem does not recur. In the firm, management respondents reported 
that most operators and many maintenance technicians were unable to analyse quality deviations systematically, and therefore unable to find root causes and achieve preventive maintenance or continuous improvement. According to managers in the production department, even Chinese engineers tended to analyse problems in a cursory manner and adjust only parameters, rather than eliminating root causes (q4, Table 1). Such superficial problem-solving had lowered the efficiency of the production system, for example through line stops, machine breakdowns, and the production of faulty parts (q5, Table 1). Due to this inattention to root causes, the same faults occurred repeatedly, leading to an unstable production process.

The interviewees attributed this lack of systematic problem-solving firstly to insufficient Lean knowledge (see Figure 1, arrow linking lack of Lean knowledge with lack of systematic problem-solving), and secondly to several institutional and cultural factors in the Chinese context. Missing industrial experience was seen to be a prime reason, but Western respondents also explained that problem-solving skills were insufficiently developed in Chinese schools and vocational education, which they believed focus on memorising facts rather than practicing analytical skills (q6, Table 1). A number of interviewees also mentioned Chinese cultural values in this context. The strong regard of 'face' (mianzi) as part of Chinese culture was seen to inhibit employees from suggesting solutions, for fear that they might appear naïve. Moreover, an emphasis on harmony and relationships was taken as explanation for Chinese employees' reluctance to reveal root causes of a problem. High power distance, in turn, was seen to prevent operators from escalating problems to higher levels and confronting a superior. Obviously, these cultural dispositions impeded Chinese employees in internalising the principles of continuous improvement. 
High employee turnover. High employee turnover strongly inhibited the participating firm in developing Lean knowledge and problem-solving skills, and technical expertise in general. Annual fluctuation rates amounted to up to 80 per cent, and skilled workers were extremely difficult to replace (q7, Table 1). Finding sophisticated labour was a challenge, and a great deal of training and time was needed before new recruits were able to start working within the Lean production system. In Lean terms, the additional training effort constituted 'waste'. The main effect of high employee turnover was however through its impact on levels of employees’ Lean knowledge (see Figure 1, arrow linking employee turnover with lack of Lean knowledge). The turnover levels had also restricted the more mature Suzhou plant from gaining any significant knowledge advantage over the less mature Changsha plant. On the shop floor, the missing experience of newly recruited operators led to quality deviations and frequent interruptions of the production flow through wrong handling of parts and resultant damage (q8, Table 1).

The interviewees attributed this high employee turnover to several root causes in the institutional context. Above all, China’s rapid economic growth had created multiple job opportunities. In the eyes of the interviewees, small salary differences were often a reason for changing employer. Due to China’s relatively recent industrialisation, there was also no wellestablished occupational image of engineers. Many engineering graduates were seen to expect management tasks from the beginning rather than hands-on production duties, which led to disappointment after recruitment (q9, Table 1). Similarly, shop-floor workers were reportedly disappointed by the unexpected hard work and routine of the assembly line. 
Disregard of procedures and standards. Successful Lean production requires employees at all levels to adhere to well-defined procedures and standards, and operators need to follow their supervisors' instructions on this matter. In the firm, however, respondents perceived that operators often did not follow management orders on procedures and standards, and that this seriously impeded successful Lean production. For example, rules of non-smoking and eating in dust-free areas were frequently broken. Workers were also seen to omit work steps and simplify their assembly tasks intentionally (q10, Table 1), knowing that the chance of getting caught by management was low.

The complex assembly processes and specified takt-times of Lean left very little space for such deviations from work instructions, thereby leading to quality problems in the final product. For example, respondents explained that operators had often disregarded the onepiece flow principle in order to gain extra break time (q11, Table 1). When a problem at a workstation occurred, they did not stop the assembly task at their own workplace to support problem-solving at the affected location. As a consequence, problem-solving took longer, and workers who continued their work had to store their semi-finished parts in the assembly line. This produced the risk of work steps being skipped and products being passed further downstream.

When using visualisation tools, some workers tended to simply 'tick off' checklists without properly engaging in the tasks required, showing a clear lack of internationalisation of this practice. Management was thereby given a wrong picture of the state of production, creating the risk of breakdowns. The researcher's own inspection of visualisation charts at the assembly lines, compared with observed problems occurring at the same lines, confirmed that the charts were overly positive. 
The respondents relegated the perceived disregard of procedures and standards to the lack of Lean knowledge (see Figure 1, arrow linking lack of Lean knowledge with disregard for procedures and standards), and to China's relatively recent industrialisation. Due to this, many Chinese employees, especially operators from an agricultural background, were unfamiliar with formal work procedures and standards. Several Chinese and German respondents also mentioned that in China, compared to the West or Japan, formal rules, such as laws and traffic rules, are generally treated as low-obligation. This in turn was ascribed to China’s relatively young legal system (q12, Table 1).

Intercultural communication difficulties. Effective interpersonal communication is essential for Lean production. Communication is important in training Lean knowledge, for supervisors to obtain their operators' suggestions as part of continuous improvement, and for ensuring that changes made within the continuous improvement process are readily accepted and implemented by employees at all levels. All interviewees reported that it was hard to achieve effective cross-cultural communication between Chinese and Western employees on the sites. Insufficient English language skills were mentioned as the primary issue, particularly amongst operators, but also with regard to some Chinese and Western office employees (q13, Table 1). In addition, the disparity between the Chinese indirect communication style and the very direct German communication style lead to misunderstandings, for example when Chinese employees perceived Germans to be too direct and therefore rude, or to be inapprehensive of the points Chinese colleagues wanted to make (q14, Table 1). Some German employees had, in turn, been irritated when they felt that Chinese colleagues did not come to the point, or when they could not judge whether their instructions had been 
understood. These difficulties in two-way communication made it hard to train and obtain Lean knowledge (see Figure 1, arrow linking intercultural communication difficulties with Lack of Lean knowledge). Communication difficulties, combined with high power distance, were also seen to hinder Western managers in obtaining any feedback and suggestions from Chinese employees, which disabled the continuous improvement process. Moreover, some of the German respondents perceived that the Chinese indirect communication style was longwinded and therefore inhibited the rapid problem-solving required for one-piece flow production (q15, Table 1).

The respondents traced the Chinese indirect communication style back to cultural roots, including Confucian values, high power distance, and a strong emphasis on 'face' and harmonious relationships (q16, Table 1). However, communication problems seemed to vary between different age groups, between the Chinese regions, and the length of collaboration. Younger employees and those from the more developed coastal regions were seen to possess better English language skills due to their greater exposure to the language. Chinese employees in the more mature Suzhou plant also reported that they had accepted the German direct communication style over time, and had even adapted to it so some extent.

Weak supplier performance. Nearly all participants at both plants reported on quality problems of mechanical parts sourced in China. Respondents explained that these quality problems emerged because the Chinese suppliers did not apply Lean principles and were unaware of the advantages of modern production systems (q17, Table 1).

Several production leaders explained that continuous monitoring of incoming supplier parts was necessary to ensure stable processes. This additional internal quality check created 
waste in the form of human effort, warehouse space and transportation. It also inhibited JIT, in particular the element of 'ship to line', where parts are delivered directly to the assembly line without additional checks, in order to minimize non-value-adding activities. High levels of supplier parts had to be stored in warehouses as safety buffers in order to balance the company's cycle time with the supplier cycle time, and provide for interruptions on the supplier's side. In Lean, such additional inventory is considered a form of waste. Moreover, by using traditional mass production, many local suppliers produced in big batches and delivered high quantities to the company's warehouse, instead of JIT delivery of small batches at higher frequency. This contradicted the principle of 'pull' by the customer, and led to high levels of scrapped material when an error occurred, and to interruptions to the one-piece production flow. As a consequence, the firm set strict rules to prevent those parts to be further processed. If a problem was detected in a supplier batch, all other parts from that batch were refused or scrapped (q18, Table 1). Some interviewees therefore concluded that without reliable suppliers who followed Lean principles, the company’s own production system could not be truly Lean.

Due to the poor reliability of local suppliers, the Chinese plants still depended on some key assembly parts or machinery spare parts from Western suppliers. These overseas deliveries, however, created additional costs and reduced flexibility, because over such distance, parts could not be delivered JIT. Additional warehouse space was required and orders needed to be placed in advance, making it impossible to achieve a continuous flow of parts.

The suppliers were seen to make little effort to restructure their production according to Lean principles. This was explained partly by their limited exposure to and knowledge of 
Lean, leading the owners of most supplier firms to persist in traditional production methods.

This attitude was reportedly reinforced by the favourable order situation for Chinese suppliers in the current situation of economic growth. Respondents explained that it was easy for suppliers to find customers with lower requirements, and supplier firms were therefore not interested in setting up long-term relations with a company requiring high quality standards, additional investments in new production methods, and raising risks of failure when implementing these methods (q19, Table 1).

\section{Discussion}

Institutional and cultural factors of Lean manufacturing in China

By interpreting our respondents’ accounts in the light of previous conceptualisations of the Chinese business system, we are able to delineate a set of interrelated institutional and cultural factors that created barriers to the transfer of Lean to China. With regard to institutional factors, four interrelated elements of the Chinese business system seem to be most relevant: China's traditional norms of management, education and legal systems, and its manufacturing norms.

As outlined by Redding and Witt (2007), China’s economy has through centuries developed on the basis of networks of family-owned businesses. In these firms, responsibility and decision-making lay primarily in the hands of the lao ban or big boss, whilst it was the employees' role to follow the boss's directions. This legacy is still apparent in the oftenobserved reluctance of Chinese employees to take initiative and own responsibility (e.g. Zimmermann et al., 2003), which has also been strongly exacerbated through China’s periods of totalitarian control, where personal opinions and initiative could lead to severe punishment 
(see Redding and Witt, 2007, 2009). Accordingly, participative management and delegation of responsibility are still not common in Chinese firms. This goes hand-in-hand with a lack of advanced skills in the Chinese workforce, with little emphasis on continuous training and long-term career perspectives within a firm (Witt and Redding, 2014:24). Importantly, China's hierarchical management is also deeply rooted in the traditional Confucian value of obedience to superiors within the societal order. It is therefore not surprising that although the firm in our study tried to apply Western management methods in line with Lean principles, these fell on infertile ground as far as initiative, participation, and retention of Chinese employees were concerned. Interestingly, our respondents additionally perceived that Chinese engineers were unfamiliar with the role of a qualified engineer in Western firms to include hard hands-on work. This misconception may accord with the traditional hierarchical status division between manual and intellectual work (e.g. Barabasch et al., 2009)

The importance of these management norms for Lean transfer becomes very clear when comparing it to the management models of Japan (Lean’s country of origin) and Germany. Both countries have a long tradition of participative management, combined with a highly skilled workforce strongly involved in decision-making and innovation of products and procedures. This workforce is commonly developed and motivated through long-term jobs, continuous training, and incentives such as reward-sharing (Redding and Witt, 2007: 57). There are notable differences between the German and Japanese management models. In particular, vocational skills training in Germany is more standardized and less firm-specific, and employees have greater opportunities to leave a firm (Streeck, 1996). Nevertheless, the similarities of the Japanese and German management models have been solid pillars of Lean production, facilitating the development of employees’ Lean understanding, initiative-taking 
and systematic problem-solving skills, as well as long employee tenure. By contrast, the Chinese management norms are in these respects incompatible with the requirements of Lean production.

Furthermore, China's educational system is an important root of Lean barriers, as it shapes the technical and problem-solving skills of Chinese employees. Traditional education followed a method of 'learning by rote and without questioning' (Redding and Witt, 2009: 391), rooted in Confucian values of obedience and reinforced through the eras of totalitarian control where questioning of official authority was prohibited and risky. Over the last two decades, engineering and managerial curricula in China have been reformed to stimulate more analytical and problem-solving skills. However, highly qualified engineers, managers, and well-trained workers are still in short supply for foreign firms (e.g. Li and Sheldon, 2011), and our findings suggest that knowledge of Lean production methods is particularly rare. This situation is aggravated by high employee-turnover levels and the lack of continuous skills training in firms (Redding and Witt, 2014: 21). Importantly, our findings suggest that in locations near the developed coastal regions, it is easier to find Chinese recruits with Westernstyle education or experience in a Western firm. However, high employee-turnover rates set a limit to continuous in-house training, also near the coastal regions.

Another important institutional factor can be seen in China’s legal system. China’s legal system has traditionally not been strong and has not created a system of 'institutionalized trust’ through rule of law (see Redding and Witt, 2014). Instead, Chinese businesses have tended to rely on personal relationships to establish trust with their circle of customers and business partners, based on norms of reciprocity (Redding and Witt, 2007). For these reasons, a disregard of formal legal rules is likely to be more acceptable in China 
compared to Western societies and Japan, which have strong legal systems and institutionalized trust. Notably, China also scores low on Hofstede’s uncertainty-avoidance dimension, whilst both Germany and Japan score very high, implying that their members tend to appreciate and follow formal rules to a much higher extent than Chinese citizens (see Hofstede, 2003). Our study suggests that low obligation to rules affected Chinese workers' adherence to Lean principles, as they did not feel morally obliged to adhere to the formal Lean principles. This effect was of course reinforced by workers' lack of understanding of the function of Lean principles.

Our study further suggests that traditional Chinese manufacturing norms, which are in stark contrast to Lean principles, still prevail in the minds of Chinese employees and supplier firms. Arguably, the Chinese mass production norms, which use large inventories as buffers between separate production steps, have in the past been developed and reinforced through China’s unpredictable political and legal systems. In times of political and legal uncertainty, mass production and the storage of large supplies may have been a safer option than JIT, low inventories and frequent delivery of small batches, which depend on high planning security. Moreover, traditional mass manufacturing relied on low-skilled workers following superiors' orders, which accorded with traditional management norms. Additionally, opportunities to experience Lean manufacturing principles in China also remain scarce. For these reasons, it is not surprising that Chinese members of the firm and supplier firms were in our cases still strongly guided by traditional norms of manufacturing, and found it hard to internalize incompatible principles of Lean, such as JIT and elimination of inventories.

Our findings highlight how certain cultural factors affected the transfer of Lean to China. Confucian values, high power distance, and the importance of maintaining face all 
prevented operators from revealing and escalating problems in the production line and voicing suggestions for improvement. This made it impossible for the firm to achieve continuous improvement targets. The situation was further aggravated by the difficulties for German managers to understand Chinese employees' indirect high-context communication style, and this made it hard for them to train Lean knowledge and gain feedback as part of the continuous improvement process. Language difficulties further fed into this issue, although they were weaker in the Suzhou plant near the coastal belt.

It is likely that China's low individualism levels contributed to Chinese employees’ reluctance to analyse problems independently and express their ideas for improvements, given that these behaviours require responsibility and initiative at individual level. Even though there is evidence that individualistic values are growing in China, its individualism scores are still lower than in Western societies (see Allik and Realo, 2004). At the same time, high collectivism in China is tied to the collectives of the family and social network (see Witt and Redding, 2014), rather than the employing firm as in Japan (see Streeck, 1996). Hence, high collectivism in China is not conducive to identification with a firm, firm loyalty, or long-term tenure.

Notably, the outlined institutional and cultural factors created barriers to Lean transfer even within our Western company context. Lean was in our cases transferred from a Western headquarters to Western-firm subsidiaries, which were managed by a significant number of Western expatriates. The expatriates in these subsidiaries had been educated either in Germany or by German managers. They were therefore familiar with the requirements of the Lean system, and tried hard to deploy their Western leadership style and reproduce the Western Lean system in the subsidiaries. Nevertheless, Chinese employees’ cognitions and 
behaviours seemed to be determined more strongly by the Chinese institutional and cultural environment. These factors are thus likely to have an even stronger influence and create greater barriers to Lean in an all-Chinese company setting, as observed in the firm's Chinese supplier firms. Hence, our Western company setting makes it particularly clear just how strong the institutional and cultural determinants of Lean transfer still are.

\section{Lean or Lean with a 'Chinese touch'?}

Given the lack of success in transferring Lean to the Chinese sites, and the host of barriers that were rooted deeply in the Chinese country context, some may wonder why the firm did not try to adapt the technical aspects of Lean to the Chinese context. Instead, the company's explicit aim was to roll out their own Lean production system worldwide, in all its international subsidiaries, and not to allow for country-specific systems. The company had even established a dedicated Lean implementation department in all plants, to ensure that the production system would be used worldwide.

This strategy of adhering to a uniform Lean system internationally, despite severe barriers, is not untypical of multinational companies within the automotive industry. It also offers certain benefits. For example, an adaptation of practices to the subsidiaries' context also makes cross-border knowledge transfer more difficult, because it increases the ‘stickiness’ of knowledge significantly (Jensen and Szulanski, 2004). The history of Lean may also explain why many manufacturing firms follow Lean production as their global production system. In 1990, Womack et al.'s publication of the results of the International Motor Vehicle Program demonstrated the superiority of Lean over traditional massproduction systems. Since then, Lean has established itself as one of the most dominant 
production paradigms of modern times (Voss, 2005). As a result of the high profile of the Toyota Lean system, most renowned globally-operating companies within the automotive industry have developed a company-specific production system, with the Toyota Production System as a raw model (Netland, 2013). Examples include Chrysler, Mercedes-Benz, Opel, Audi, Volkswagen, Ford, and Hyundai. These global companies have also adhered to a single Lean system worldwide and have not adjusted their production system to subsidiary contingencies (Netland, 2013).

In view of this common practice in the automotive industry, it is not surprising that the host company took their standard Lean production system as a strategic practice and directed a great deal of effort to implementing it in China, without technical adaptation. However, the question remains whether it is, in the long run, better for multinational companies to adopt the HQ's original production system worldwide, or to adapt their production system to other contexts. Researchers have tried to answer this question theoretically in terms of the 'Lean adoption vs. Lean adaption debate’ within operations management (e.g. Sandberg, 2007; Jürgens, 2003; Cooney, 2002), without reaching a common conclusion. Regardless of the answer, it is crucial for manufacturing firms to understand the barriers to transferring Lean systems to another country context in order to deal with them, whether by training and developing their local workforce to adapt to the Lean system, or by adapting the technical system to the prerequisites of the local workforce.

This study suggests that it is necessary to adjust and redesign at least certain elements of the Lean system. On the one hand, certain elements of the Chinese environment are likely to change in the near future. The English language skills and intercultural experience of educated Chinese employees are improving rapidly, which will lessen intercultural 
communication barriers. Moreover, increasing exposure to Western production methods, including Lean, may raise the levels of lean understanding among employees and supplier firms. Also, the supplier firms’ market environment may not remain as favourable, making them more inclined to develop long-term relationships with Western firms that demand Lean procedures. On the other hand, changes in the systems of management, legislation, and education will take a long time, given their embeddedness in the long history of China's institutions and culture (see Redding and Witt, 2007, 2009). Similarly, cultural values like power distance and face are unlikely to change dramatically in the near future, and will perpetuate behaviours that stand against Lean principles.

The challenge will therefore be to adapt the Lean system to the Chinese context, without interfering with the technical aspects of Lean that are interdependent. To achieve onepiece flow, for example, high levels of equipment reliability are prerequisite. Technical staff and Lean implementation teams need to achieve a challenging balance between retaining the global production standards set by headquarters, retaining the coherence of the Lean system, and adapting the production system to the context of the local country.

For this purpose, it may be necessary to maintain tighter managerial control than envisaged in the lean philosophy. Lean-experienced managers rather than workers may have to take responsibility for guarding Lean principles in the production line, such as one-piece flow and total maintenance. Obviously, however, this will not stop supplier firms’ nonadherence to Lean. Our view is therefore that a compromise has to be found between Lean principles and local conditions within and around the firm. In this sense, manufacturing in China cannot at present be strictly 'Lean'. 
Taking a broader perspective, we can infer certain consequences for China’s technological development at a larger scale. It has previously been outlined that technical innovation, research, and development in China are constrained through China's institutional context, for example the lack of institutionalized trust through a strong legal system, and the lack of funding through access to loans for entrepreneurs (Witt and Redding, 2014). Redding and Witt (2007: 227) therefore argue that China's main competitive advantage is likely to remain for some time in its performance as the 'assembly workshop of the world' rather than in high-end innovative technology. At the same time, multinational enterprises are an important source of technological know-how for China, which they transfer both directly (for example through partnerships with Chinese firms or technological training centres), and indirectly through knowledge spill-overs (Giroud, 2014). Our findings add a new insight to these propositions. They suggest that even for the manufacturing sector, the Chinese context poses significant barriers as far as Lean production methods are concerned. Moreover, these barriers appear to exist even within Western firms in China (as opposed to Chinese firms), disabling them from transferring their Lean production methods to the Chinese context. This does not put China's position as the assembly workshop of the world into question, but it demonstrates that we have to differentiate between different forms of production. Lean production, which may be the most efficient method for manufacturing high-end technological products, is likely to remain highly constrained for China in the near future, and this holds for both Western and local firms.

\section{Contributions to research}


Based on our in-depth case study evidence, we were able to provide a systematic overview of barriers to the transfer of a Lean production system to China (RQ1), the effect of these barriers on particular Lean principles (RQ2), and their roots in the Chinese institutional and cultural context (RQ3).

Some of the barriers that we have highlighted mirror those found in prior research. The reviewed studies on Lean manufacturing in China describe a lack of Lean knowledge, high employee turnover, and weak supplier performance in a similar way to our respondents. Moreover, the previously observed lack of initiative and participation are in our study elements of the barrier 'lack of systematic problem-solving', and the tolerance for untidiness is part of 'disregard of procedures and standards'. Interestingly, prior studies on Lean in China identified three barriers likely to be specific to Chinese firms, and were therefore not present in our cases. Non-participative management, a missing long-term strategy, and inadequate quality-control procedures are likely to be less established and create greater barriers in Chinese firms that try to adopt Lean manufacturing methods, compared to the subsidiaries of a wholly-owned foreign company largely managed by Western expatriates. Furthermore, we revealed ‘intercultural communication’ as an additional barrier to Lean transfer, which is likely to be specific to the Western-Chinese setting in our Western subsidiary cases. Our study goes beyond prior research on Lean manufacturing in China by providing more detailed descriptions of the effects that the barriers have on the transfer of particular Lean principles and, most importantly, by explaining the barriers through Chinese context factors.

Our study further contributes to transnational practice transfer theory (Kostova, 1999), by extending it to the particular practice of Lean production in the particular context of China. Whilst there is a large body of research on institutional and cultural factors affecting the 
transnational transfer of other organisational practices to China, especially human resource management practices (e.g. Gamble, 2010; Yu and Meyer-Ohle, 2008; Schmidt et al., 2013), the same cannot be said for the transfer of Lean. In the same vein, there are several thorough investigations of the transfer of Lean manufacturing from Japan to Western countries, including the US (see Holweg, 2007) and Germany (Streeck, 1996), but we believe that our study is the first to systematically analyse the transfer of Lean to China.

We also go beyond the institutional distance construct used in prior practice-transfer studies (e.g. Eden and Miller, 2004; Kostova, 1999; Peng et al., 2008), by defining a particular set of interrelated institutional and cultural factors that are relevant for this particular practice transfer. This approach is in line with Jackson and Deeg's (2008) concern that institutional-distance measures do not take into account the specific features of particular countries' institutions that affect transnational practice transfer. It has to be noted that the institutional and cultural distance between Germany and China is indeed large (e.g. Chao and Kumar, 2010), which also became apparent in our description of institutional and cultural context factors above. In line with practice-transfer theory (Kostova, 1999), this distance between the institutional and cultural context of the home unit (Germany) and the recipient unit (China) can explain why certain Chinese context factors created barriers to the transfer of Lean. However, we needed a more detailed description of relevant context factors, rather than an aggregate measure of institutional distance, in order to reveal the mechanisms by which these context factors affected Lean transfer. Moreover, we had to understand how the context factors were interrelated in order to estimate their future changes and speculate on the chances of Lean being successful in China in the near future. 
We further contribute to the literature on national business systems. Firstly, we analyse how certain institutional and cultural elements of the Chinese business system are relevant in the case of transnational transfer of Lean practices. Secondly, we demonstrate how these institutional and cultural elements of the business system shape certain cognitive dispositions and behaviours of members of this business system, in our case Chinese employees and managers of the firm and supplier firms. This enabled us to point out that the elements of the business system affected organisational-level practice transfer via their influence on individuals. It was their cognitive dispositions and behaviours, shaped by their institutions and culture, which acted as barriers to the implementation and internalisation of the Lean system. Such a micro-level analysis has so far not played a significant part in business system models (see Witt and Redding, 2014).

\section{Limitations and suggestions for future research}

Our model of barriers to Lean transfer in the Chinese context is based on research in two plants of one firm, in two different locations in China. Using such a case-study methodology was appropriate for pursuing the under-explored research questions, for gaining an in-depth understanding of the mechanisms by which Lean barriers affect certain Lean elements, and for exploring how the barriers were tied to certain country-context factors. As with all case studies, however, further research is required to examine the transferability of findings to other settings (see Lincoln and Guba, 1999). Future research could investigate whether the model is also applicable in other regions in China, such as other inland, newly-developed industrial areas, or in other major cities. Furthermore, it is possible that at least parts of our model may be transferable to other emerging economies, such as Brazil, Mexico, and India, 
which have parallels in their socio-economic context. Future research could also investigate the model's transferability to firms headquartered in other highly industrialized nations, such as other European countries, the US, and Japan, which have developed different variants of Lean manufacturing. The need to explore Lean adaption reflects wider debates within the Lean community about how Lean adaption is managed within different contexts that are country-based and sector-based (e.g., Joosten et al., 2009; Jürgens, 2003). Future research could compare and draw parallels between these types of adaption.

From a methodological perspective, our interviews with Chinese respondents were to some degree constrained through language barriers, with regard to shop-floor workers as well as the office level. By adjusting the wording of the questions, and with the help of Chinese speakers, the interviewer was able to make good sense of their responses. However, it was difficult and at times impossible to gather the culturally-specific meanings of the Chinese respondents' replies. To overcome these issues, a Chinese interviewer would be necessary. Chinese language interviews are also a prerequisite for gaining access to shop-floor workers, whose cognitions and behaviour are particularly important in Lean production (e.g. Aoki, 2008), and whose perspective should therefore be ideally obtained first-hand.

The majority of data was collected within a single research trip, which did not allow us to systematically explore changes in barriers or country-context factors over time. By comparing a more and a less mature plant, and by interviewing employees who had worked for the host company for several years, we were able to pinpoint certain ways in which country-context factors and barriers had changed over the previous couple of years. Moreover, signs of change became visible through our comparison between the two plants, one near the more developed coastal region, and the other in the less developed central part of China. Our 
findings thus suggest that in the future, intercultural communication difficulties will decrease, and there will be a rise in the understanding of Western management norms and Lean methods. At the same time, this change will be restrained by China's cultural and institutional roots. Future inquiries will need to deploy a longitudinal research design to examine the pattern of changes in barriers and underlying Chinese context factors over time, and to diagnose any other directions of change.

\section{Notes}

1. We use the term 'employee' to include all levels of the hierarchy.

2. It should be noted that this perception is not in line with all current Chinese engineering curricula.

\section{References}

Allik, J. and Realo, A. (2004) Individualism-collectivism and social capital. Journal of CrossCultural Psychology 35(1): 29-49.

Aminpour, S. and Woetzel, J.R. (2006) Applying Lean manufacturing in China. McKinsey Quarterly 2(1): 106-115.

Aoki, K. (2008) Transferring Japanese kaizen activities to overseas plants in China. International Journal of Operations and Production Management 28 (6): 518-539.

Barabasch, A., Huang, S. and Lawson, R (2009) Planned policy transfer: The impact of the German model on Chinese vocational education. Compare 39(1): 5-20.

Bicheno, J. and Holweg, M. (2009) The new Lean toolbox. Towards fast, flexible flow. Buckingham: Picsie. 
Brown, G. and O’Rourke, D. (2007) Lean manufacturing comes to China. International Journal on Occupation and Environmental Health 13(3): 249-254.

Cantwell, J., Dunning, J.H. and Lundan, S.M. (2010) An evolutionary approach to understanding international business activity: The co-evolution of MNEs and the institutional environment. Journal of International Business Studies 41: 567-586

Chao, M. Ch.-H. and Kumar, V. (2010) The impact of institutional distance on the international diversity-performance relationship. Journal of World Business 45: 93103.

Chen, L. and Bo, M. (2008) How to make 5S as a culture in Chinese enterprises. Innovation Management 3: 221-224.

Chin, K.S. and Pun, K.F. (2002) A proposed framework for implementing TQM in Chinese organizations. International Journal of Quality and Reliability Management 19(3): 272-294.

Comm, C.L. and Mathaisel, D.F.X. (2005) An exploratory analysis in applying Lean manufacturing to a labor-intensive industry in China. Asia Pacific Journal of Marketing and Logistics 17(4): 63-80.

Cooney, R. (2002) Is 'Lean' a universal production system? Batch production in the automotive industry. International Journal of Operations and Production Management 22(10): 1130-1147.

Denzin, N.K. and Lincoln, Y.S. (1994) Handbook of Qualitative Research. London: Sage. 
Eden, L. and Miller, S.R. (2004) Distance matters: Liability of foreignness, institutional distance and ownership strategy. Bush School of Government and Public Service, Texas A\&M University Working Paper 404.

Gamble, J. (2010) Transferring organizational practices and the dynamics of hybridization: Japanese retail multinationals in China. Journal of Management Studies 47(4): 705732.

Gaur, A.S., Delios, A. and Singh, K. (2007) Institutional environments, staffing strategies, and subsidiary performance. Journal of Management 33(4): 611-636.

Giroud, A. (2014) MNEs in Asian business systems. In M.A. Witt and G. Redding (eds.) The Oxford Handbook of Asian Business Systems. Oxford: Oxford University Press, pp.441-464.

Geertz, C. (1973) The Interpretation of Cultures. New York: Basic Books.

Hofstede, G. (2003) Culture's Consequences. Comparing Values, Behaviors, Institutions, and Organizations across Nations. London: Sage.

Hofstede, G., Van Deusen, C., Mueller, C., Charles, T. and Business Goals Network (2002) What goals do business leaders pursue? A study in fifteen countries. Journal of International Business Studies 33(4): 785-803.

Holweg, M. (2007) The genealogy of lean production. Journal of Operations Management 25: 420-437.

Jackson, G. and Deeg, R. (2008) Comparing capitalisms: Understanding institutional diversity and its implications for international business. Journal of International Business Studies 39(4): 540-561. 
Jensen, R. and Szulanski, G. (2004) Stickiness and the adaptation of organizational practices in cross-border knowledge transfers. Journal of International Business Studies 35: 508-523.

Joosten, T., Bongers, I. and Janssen, R. (2009) Application of Lean thinking to healthcare: issues and observations. International Journal for Quality in Health Care 21(5): 341347.

Jürgens, U. (2003) Characteristics of the European automotive system: is there a distinctive European approach? Discussion Paper, Research Unit: Knowledge, Production Systems and Work 2003(3). Berlin: Social Science Research Centre.

Kostova, T. (1999) Transnational transfer of strategic organizational practices: A contextual perspective. Academy of Management Review 24(2): 308-324.

Lee, C.Y. (2004) Perception and development of total quality management in small manufacturers: An exploratory study in China. Journal of Small Business Management 42(1): 102-116.

Li, Y. and Sheldon, P. (2011) Skill shortages: Where labour supply problems meet employee poaching. In P. Sheldon, S. Kim, Y. Li and M. Warner (eds.) China’s Changing Workplace: Dynamism, Diversity and Disparity. London: Routledge, pp.129-143.

Liker, J. and Meier, D. (2007) 'Toyota Talent': Developing your people the Toyota way. New York: McGraw-Hill.

Lincoln, Y. and Guba, E. (1999) Establishing trustworthiness. In A. Bryman and R. Burgess (eds.), Qualitative Research. London: Sage, pp.397-444, 
Netland, T. (2013) Exploring the phenomenon of company-specific production systems: onebest-way or own-best-way? International Journal of Production Research 51(4): 1084-1097.

Ohno, T. (1988) Toyota production system: Beyond large-scale production productivity. New York: Productivity Press.

Oliver, N., Delbridge, R. and Lowe, J. (1998) Inside the Chinese automotive industry: The third lean enterprise report. London: Andersen Consulting.

Paolini, A., Leu B. and Chinn, R. (2005). Exporting Lean to China: Know before you go. Available http://www.6sq.net/question/53753, accessed 4 December, 2014.

Peng, M.W., Wang, S.Y.L. and Jiang, Y. (2008) An institution-based view of international business strategy: A focus on emerging economies. Journal of International Business Studies 39: 920-936.

Redding, G. and Witt, M.A. (2007) The Future of Chinese Capitalism: Choices and Chances. Oxford: Oxford University Press.

Redding, G. and Witt, M.A. (2009) China’s business system and its future trajectory. Asia Pacific Journal of Management 26:381-399.

Sandberg, Å. (2007) Enriching Production. Perspectives on Volvo's Uddevalla plant as an alternative to Lean production. Aldershot: Avebury.

- Schmidt, C., Mansson, S. and Dolles, H. (2013) Managing talents for global leadership

positions in MNCs: Responding to the challenges in China. Asian Business \& Management 12: 477-496

Schwandt, T. (2007) The Sage dictionary of qualitative inquiry. Thousand Oaks, CA: 
Sage.

Scott, W.R. (1995) Institutions and Organizations. London: Sage.

Slack, N., Chambers, S. and Johnston, R. (2004) Operations Management. Harlow: Pearson Education.

Streeck, W. (1996) Lean production in the German automobile industry: A test case for convergence theory. In S. Berger and R. Dore (eds.) National Diversity and Global Capitalism. Ithaca: Cornell University Press, pp.197-219.

Taj, S. (2005) Applying Lean assessment tools in Chinese hi-tech industries. Management Decision 43(4): 628-643.

Voss, C.A. (2005) Alternative paradigms for manufacturing strategy. International Journal of Operations and Production Management 25(12): 1211-1222.

Witt, M.A. and Redding, G. (2014) China. Authoritarian capitalism. In M.A. Witt and G. Redding (eds.) The Oxford Handbook of Asian Business Systems. Oxford: Oxford University Press, pp.11-32.

Womack, J.P. and Jones, D.T. (2003) Lean thinking: Banish waste and create wealth in your corporation. New York: Free Press.

Womack, J.P., Jones, D.T. and Roos, D. (1990) The Machine that changed the World. New York: Rawson Associates.

Wong, M. (2007) The role of culture in implementing Lean production system. In

J. Olhager and F. Persson (eds.) IFIP International Federation for Information Processing Vol.246. Boston: Springer, pp.413-422..

Yin, R.K. (2003) Applications of Case Study Research. London: Sage.

Yu, J. and Meyer-Ohle, H. (2008) Working for Japanese corporations in China: A qualitative 
Study. Asian Business and Management 7: 33-51.

Zimmermann, A., Holman, D. and Sparrow, P.R. (2003) Unravelling adjustment mechanisms: Adjustment of German expatriates to intercultural interactions, work, and living conditions in the People’s Republic of China. International Journal of Cross Cultural Management 3(1): 45-66. 


\begin{tabular}{|c|c|c|c|}
\hline \multicolumn{4}{|l|}{ Changsha plant } \\
\hline Department & Position & German/Western & Chinese \\
\hline Engineering & Management & 1 German & 1 \\
\hline \multirow{2}{*}{ Manufacturing } & Management & 4 German / 1 Spanish & \\
\hline & Office level & 2 German & 8 \\
\hline HR & Management & 1 German & \\
\hline Purchasing & Office level & 4 German & \\
\hline Logistics & Office level & 3 German & 3 \\
\hline Quality management & Office level & & 2 \\
\hline $\begin{array}{l}\text { Cross-divisional Lean } \\
\text { expert team }\end{array}$ & Office level & & 1 \\
\hline \multicolumn{4}{|l|}{ Suzhou plant } \\
\hline Department & Position & German/Western & Chinese \\
\hline \multirow[t]{2}{*}{ Engineering } & Management & & 1 \\
\hline & Office level & & 5 \\
\hline \multirow[t]{2}{*}{ Manufacturing } & Management & 1 German & 1 \\
\hline & Office level & & 8 \\
\hline \multirow[t]{2}{*}{ HR } & Management & 1 German & 1 \\
\hline & Office level & & 3 \\
\hline Purchasing & Office level & 1 French & \\
\hline \multirow{2}{*}{$\begin{array}{l}\text { Cross-divisional Lean } \\
\text { expert team }\end{array}$} & Management & & 1 \\
\hline & Office level & & 6 \\
\hline
\end{tabular}

\section{Author profiles}

Dr Angelika Zimmermann is a Senior Lecturer in International Business \& Strategy in the School of Business and Economics, Loughborough University, UK. Her research focuses on international collaboration in global teams and offshoring relationships, with a special interest in the Chinese, Indian, German, and UK contexts. Her research has been widely published in international journals.

Dr Marc Fabian Bollbach is a partner in the engineering corporation Service für Gasaufbereitung, GmbH in St. Wendel, Germany. He received his MSc and PhD at Loughborough University, School of Business and Economics, UK, and he holds a Diploma in Automotive Engineering from the University of Applied Sciences Cologne, Germany. His research interests are in the area of automotive technology and Lean manufacturing processes, with a particular focus on Germany and China. 


\section{Lean principles}

Waste elimination

Production levelling

Preventive maintenance

One-piece-flow

Continuous improvement

Root cause analysis

Visualisation

Just in time
Implementation

barriers

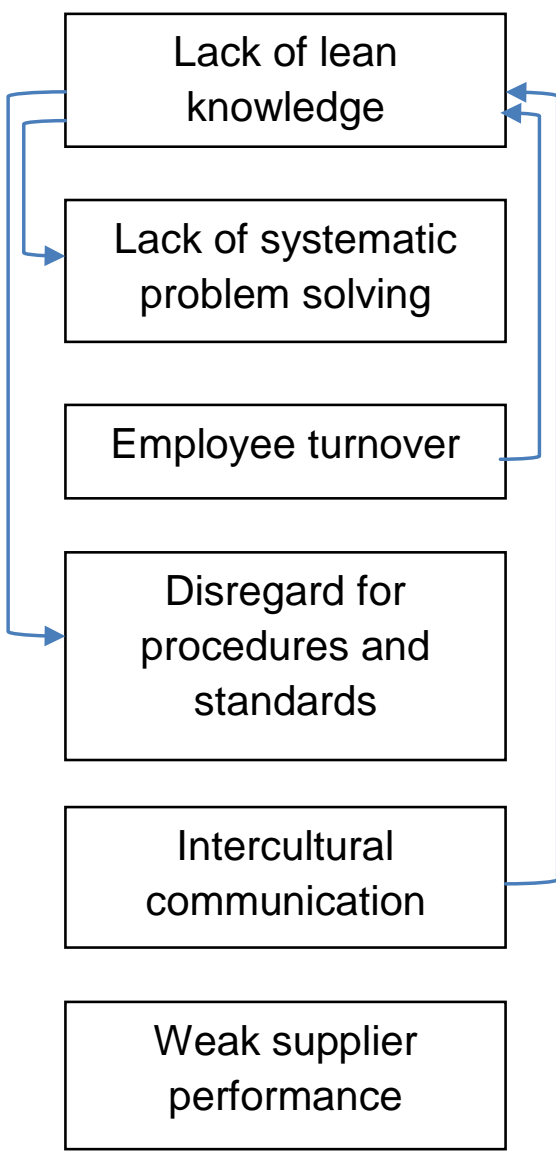

Context factors

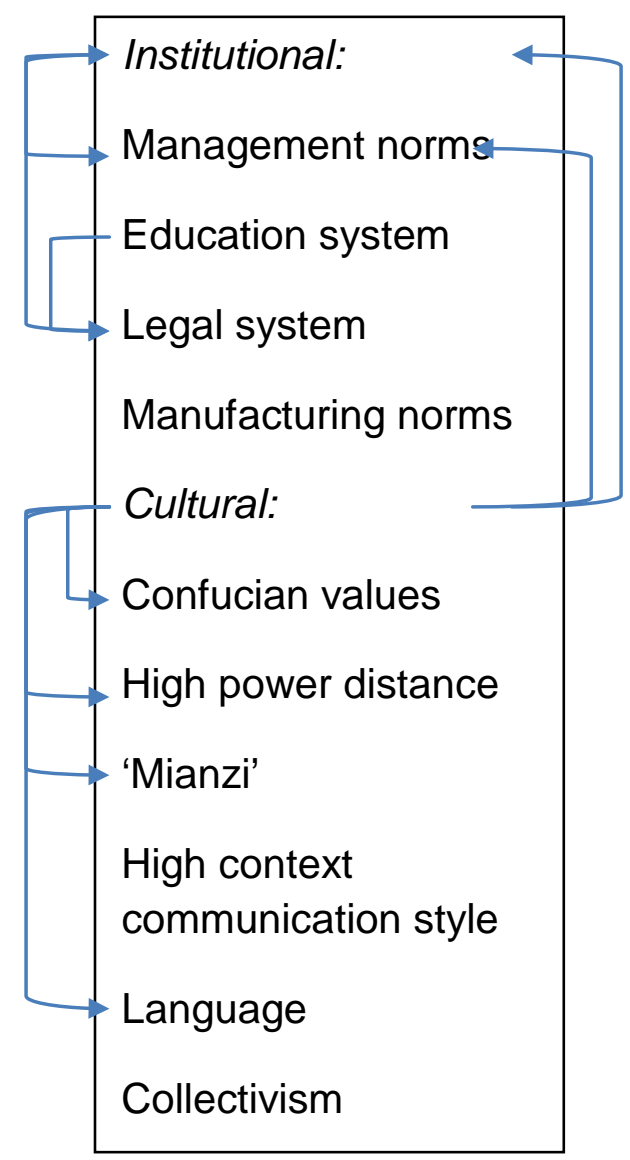


Figure 1. Overview of barriers, effects on lean principles, and context factors. 
Table 1. Illustrative quotes

\begin{tabular}{|c|c|c|c|}
\hline \multirow{2}{*}{$\begin{array}{l}\text { Implementation } \\
\text { barrier }\end{array}$} & \multicolumn{3}{|l|}{ Illustrative quotes } \\
\hline & Barrier description & Effect on Lean & Country context factors \\
\hline $\begin{array}{l}\text { Lack of Lean } \\
\text { knowledge }\end{array}$ & $\begin{array}{l}\text { (1) "The major challenge to us is to } \\
\text { make the people have real Lean } \\
\text { thinking. ... I have the feeling } \\
\text { sometimes some young engineers } \\
\text { think that Lean means an additional } \\
\text { job on top of their daily tasks } \\
\text { because they think 'oh Lean asked } \\
\text { me to do this and that'. They don't } \\
\text { realise the benefit. ... So l've tried a } \\
\text { lot to gain Lean thinking. ... To make } \\
\text { them understand and to establish } \\
\text { the magic of Lean thinking is the } \\
\text { most difficult portion of the whole } \\
\text { job." } \\
\text { Chinese manager in Changsha }\end{array}$ & $\begin{array}{l}\text { (2) “... if you say 'okay we have to } \\
\text { eliminate, reduce the scrap' ... then } \\
\text { everybody will realise 'yes this is } \\
\text { waste'. But invisible waste, for } \\
\text { example transportation, storage and } \\
\text { so on, it's not fully understood in our } \\
\text { organization, like the logistics. I told } \\
\text { them a lot of times 'why you are } \\
\text { moving the parts from this location } \\
\text { to that location? Why do you have to } \\
\text { move it? I told them; 'Why did you not } \\
\text { move this directly to the usage } \\
\text { position and so on?' This is really not } \\
\text { fully understood, what is the waste, } \\
\text { invisible waste?" } \\
\text { Chinese engineer in Changsha }\end{array}$ & $\begin{array}{l}\text { (3) "When we talk with the operators, } \\
\text { we find ... they sometimes cannot } \\
\text { understand what we are trying to } \\
\text { explain to them. ... From my } \\
\text { understanding one explanation for } \\
\text { that is the very basic general } \\
\text { education most operators had." } \\
\text { Chinese engineer in Changsha }\end{array}$ \\
\hline $\begin{array}{l}\text { Lack of } \\
\text { systematic } \\
\text { problem solving }\end{array}$ & $\begin{array}{l}\text { (4) "We have a huge problem here. } \\
\text {.. The process engineers tend to } \\
\text { adjust parameters on the machinery } \\
\text { without even knowing if that solves } \\
\text { the problem in the long run. Without } \\
\text { checking the root cause of the } \\
\text { problem, they just try different } \\
\text { things. They randomly change }\end{array}$ & $\begin{array}{l}\text { (5) "The lack of problem solving skills } \\
\text { has effects on the production. For } \\
\text { example, a machine was not running } \\
\text { in the production line. Faulty product } \\
\text { parts with wrong dimensions restricted } \\
\text { some machine parts. The machine } \\
\text { parts could not reach a sensor. The } \\
\text { machine indicates a problem with }\end{array}$ & $\begin{array}{l}\text { (6) "I believe a big part of this is due } \\
\text { to their education system. ... In } \\
\text { Germany, we start to learn this } \\
\text { already in primary school. We need to } \\
\text { solve our maths homework in three } \\
\text { steps, question, equation, answer... } \\
\text { Questioning problems, or } \\
\text { independently looking into a problem, }\end{array}$ \\
\hline
\end{tabular}




\begin{tabular}{|c|c|c|c|}
\hline & $\begin{array}{l}\text { machine settings and see if the } \\
\text { workstation starts working again. } \\
\text { They don't know what they are } \\
\text { doing. I continually try to explain how } \\
\text { to solve problem systematically, but } \\
\text { they always think the machine itself } \\
\text { is the problem. That's a general } \\
\text { problem among Chinese... They } \\
\text { adjust machine parameters until } \\
\text { somehow the machine works, then } \\
\text { they say 'great, now it works again'. } \\
\text { But two hours or two days later, the } \\
\text { problem is back and everything is } \\
\text { worse." } \\
\text { German engineer in Changsha }\end{array}$ & $\begin{array}{l}\text { the process, and what do the } \\
\text { Chinese do? They mill the mechanical } \\
\text { machine end stop away! Now the } \\
\text { machine reaches the sensor again, } \\
\text { but nobody realises that the supplier } \\
\text { parts have the wrong dimensions. } \\
\text { They did not consider that the incident } \\
\text { occurred straight after new parts were } \\
\text { delivered to the line." } \\
\text { German manager in Changsha }\end{array}$ & $\begin{array}{l}\text { I personally believe that doesn't exist } \\
\text { in Chinese education. The personal } \\
\text { drive to get to the bottom of a problem } \\
\text { and solve it, that's what I miss among } \\
\text { my subordinates." } \\
\text { German manager in Changsha }\end{array}$ \\
\hline $\begin{array}{l}\text { Employee } \\
\text { turnover }\end{array}$ & $\begin{array}{l}\text { (7) "It is a big problem first to find } \\
\text { good employees and then to keep } \\
\text { them. Here in Suzhou's industrial } \\
\text { park, there is a high fluctuation. } \\
\text { When considering changing } \\
\text { personnel and to implement } \\
\text { elements of Lean manufacturing, } \\
\text { such as standardised work, } \\
\text { importance of expert knowledge, } \\
\text { and process repeatability, then we } \\
\text { have a huge problem! This gives me } \\
\text { big headaches at the moment. My } \\
\text { division's fluctuation is half of the } \\
\text { Suzhou average, but that's still far }\end{array}$ & $\begin{array}{l}\text { (8) "... To do the work, you need to } \\
\text { be experienced. If suddenly a new } \\
\text { operator joins the line, the whole flow } \\
\text { will be interrupted until the newcomer } \\
\text { has the experience and knows what to } \\
\text { do." } \\
\text { German engineer in Changsha }\end{array}$ & $\begin{array}{l}\text { (9) "In Chinese Universities the } \\
\text { students think when you are working } \\
\text { at western companies, you go with } \\
\text { your briefcase to work, you sit in your } \\
\text { very bright office, just having a cup of } \\
\text { coffee there. Every day you just speak } \\
\text { English with your colleagues and do } \\
\text { 'trading" with other companies. But if } \\
\text { they join the factory and realise that } \\
\text { engineers need to work with their } \\
\text { hands on machines, with grease, oil, } \\
\text { and dealing with operators, they get } \\
\text { very disappointed." } \\
\text { Chinese engineer in Changsha }\end{array}$ \\
\hline
\end{tabular}




\begin{tabular}{|c|c|c|c|}
\hline & $\begin{array}{l}\text { too high for implementing Lean." } \\
\text { German manager in Suzhou }\end{array}$ & & $\begin{array}{l}\text { (involved in the company's graduate } \\
\text { scheme) }\end{array}$ \\
\hline $\begin{array}{l}\text { Disregard for } \\
\text { procedures and } \\
\text { standards }\end{array}$ & $\begin{array}{l}\text { (10) "For example, ... if you ask } \\
\text { them to make an operation } \\
\text { according to standard work. At the } \\
\text { first day they do it, but after two days } \\
\text { they will make it out of their own } \\
\text { experience. They will say 'I will do it } \\
\text { different, that is more convenient for } \\
\text { me'. " } \\
\text { Chinese engineer in Changsha }\end{array}$ & $\begin{array}{l}\text { (11) "We want to produce } \\
\text { according to one-piece flow. For } \\
\text { example there are three stations in } \\
\text { total. The station one has some } \\
\text { problems or they are interrupted by } \\
\text { maintenance or other guys. However, } \\
\text { the second operator and the third } \\
\text { operator will still continue to work } \\
\text { because they don't want to lose their } \\
\text { time in the traditional sense. Because } \\
\text { they might think; 'If I do finish my work } \\
\text { there, I can get more break time'. But } \\
\text { actually according to Lean concept, } \\
\text { they shouldn't do this. If station one } \\
\text { stops, they should stop immediately } \\
\text { and join problem solving. ... We } \\
\text { have trained them for a long time but } \\
\text { they still don't follow the rules." } \\
\text { Chinese engineer in Suzhou }\end{array}$ & $\begin{array}{l}\text { (12) "China has a long history, } \\
\text { but China doesn't have a long history } \\
\text { of 'following the law'. There were } \\
\text { times when China didn't have a very } \\
\text { strict law system. Chinese people } \\
\text { followed the leader. They were } \\
\text { managed according to the leader and } \\
\text { not according to the law. ... That's } \\
\text { why Chinese people don't obey the } \\
\text { law so strictly. Chinese culture has a } \\
\text { long history, but we don't have this } \\
\text { kind of law management." } \\
\text { Chinese engineer in Suzhou }\end{array}$ \\
\hline $\begin{array}{l}\text { Intercultural } \\
\text { communication }\end{array}$ & $\begin{array}{l}\text { (13) "One major barrier is } \\
\text { definitely the language barrier. In my } \\
\text { job, I work closely with maintenance } \\
\text { technicians within the shop floor, } \\
\text { and among shop floor employees, } \\
\text { there are very little English language } \\
\text { skills. The younger guys might } \\
\text { speak a bit of English, but I often still } \\
\text { need to consult one of our }\end{array}$ & $\begin{array}{l}\text { (14) "Communication is the old } \\
\text { problem. (...) The way of the German } \\
\text { communication style is sometimes too } \\
\text { strict that the other ideas have no } \\
\text { chance to get accepted. My ideas are } \\
\text { sometimes completely thought } \\
\text { through, they are so strict. ... But if } \\
\text { I suggest my ideas to the Germans, } \\
\text { in the first step when I am still }\end{array}$ & $\begin{array}{l}\text { (16) "The indirect style of } \\
\text { communication can be explained by } \\
\text { the Chinese traditional customs. ... in } \\
\text { China it is important that you keep a } \\
\text { good relation, not argue so much. } \\
\text { This is a Chinese tradition, but that is } \\
\text { different than in Germany." } \\
\text { Chinese engineer in Changsha }\end{array}$ \\
\hline
\end{tabular}




\begin{tabular}{|c|c|c|c|}
\hline & $\begin{array}{l}\text { translators from the offices to help } \\
\text { me out. To communicate with the } \\
\text { shop floor, I need to use hands and } \\
\text { feet ... that takes a lot of time and a } \\
\text { lot of effort." } \\
\text { German engineer in Changsha }\end{array}$ & $\begin{array}{l}\text { speaking about the detail, but the } \\
\text { conclusion is not speaking out yet, } \\
\text { then they may stop the } \\
\text { communication and my raw idea of } \\
\text { the conclusion is still not being } \\
\text { communicated out." } \\
\text { Chinese engineer in Changsha } \\
\text { "When we have a problem in } \\
\text { (15) "We production, we need to solve it as } \\
\text { theon as possible. If we can discuss } \\
\text { the problems in a straight and direct } \\
\text { manner, it's easier to find a solution. If } \\
\text { we avoid conflicts and not discussing } \\
\text { problems to the point then we lose } \\
\text { time until we are in big trouble!" } \\
\text { German manager in Changsha }\end{array}$ & \\
\hline $\begin{array}{l}\text { Weak supplier } \\
\text { performance }\end{array}$ & $\begin{array}{l}\text { (17) "I personally went to a lot } \\
\text { of Chinese suppliers to see if } \\
\text { they applied Lean principles in their } \\
\text { production; they showed me } \\
\text { difficulties or gave some excuses. } \\
\text { For example, the buffer areas in the } \\
\text { suppliers' production area...that's a } \\
\text { complete mess! They do not have } \\
\text { "FIFO" [First in first out] at all. The } \\
\text { problem is that there is a high risk } \\
\text { to mix different parts and materials." } \\
\text { Chinese engineer in Changsha }\end{array}$ & $\begin{array}{l}\text { (18) "The Chinese suppliers } \\
\text { can't deliver their products in the } \\
\text { quantity and in the quality and in the } \\
\text { frequency we require. Our company is } \\
\text { in fact Lean; our internal processes } \\
\text { are following Lean principles. } \\
\text { However, the local suppliers are still } \\
\text { producing in big batches. In order to } \\
\text { fulfil our circle time, the supplier has to } \\
\text { build up inventory within our storage } \\
\text { areas. That is not Lean, because we } \\
\text { do not reduce our inventory and } \\
\text { consequently waste is generated. }\end{array}$ & $\begin{array}{l}\text { (19) 'Why do our local suppliers } \\
\text { not adopt Lean principles? Because } \\
\text { they want to make quick money! If we } \\
\text { give them a big order today and say } \\
\text { 'Okay, you can get our order but you } \\
\text { must implement Lean principles', most } \\
\text { suppliers are not interested. ... I think } \\
\text { it's particularly Chinese, because in } \\
\text { the Chinese industry there are still } \\
\text { suppliers who produce according to } \\
\text { their current mass production } \\
\text { principles and also are able to make } \\
\text { money. So they think 'why should I }\end{array}$ \\
\hline
\end{tabular}




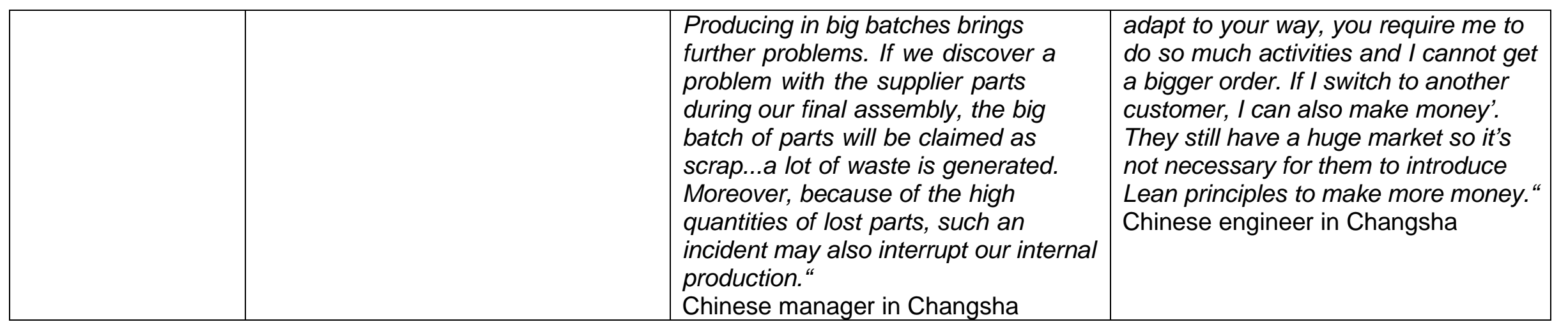

